\title{
Spor Bilimleri Fakültesi Öğrencilerinin Taraftarı Oldukları Futbol Takımına Karşı Psikolojik Bağlılıklarının İncelenmesi*
}

\author{
DOI: 10.26466/opus.623549
}

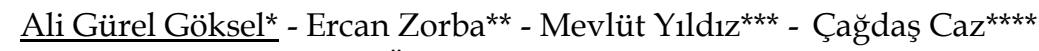

* Doç. Dr. Muğla Sıtkı Koçman Üniversitesi, Spor Bilimleri Fakültesi, Muğla / Türkiye E-Posta: gurelgoksel@gmail.com ORCID: 0000-0002-3873-1322

** Doç. Dr. Muğla Sıtkı Koçman Üniversitesi, Spor Bilimleri Fakültesi, Muğla / Türkiye E-Posta: ezorba@mu.edu.tr ORCID: 0000-0002-7864-0556

*** Arş. Gör. Dr. Muğla Sıtkı Koçman Üniversitesi, Spor Bilimleri Fakültesi, Muğla / Türkiye

E-Posta: mevlutyildizz@gmail.com ORCID: 0000-0002-1910-0330

**** Doç. Dr. Yozgat Bozok Üniversitesi, Beden Eğitimi ve Spor Yüksekokulu, Yozgat/ Türkiye

E-Posta cagdas.caz@bozok.edu.tr ORCID: $\underline{\text { 0000-0003-0262-6114 }}$

$\ddot{\mathrm{O} z}$

Günümü̈ spor endüstrisinde en önemli branşlardan biri olan futbolun, bu kadar popüler olmasın sağlayan ve futbol kulüplerinin ekonomik olarak da ayakta durmalarmı sağlayan unsur hiç şüphe yok ki kulübün sahip olduğu taraftarlarıdır. Bu sebeple futbol kulüplerinin en temel gelir kaynağı ve hedef kitlesi olan taraftarların görmezden gelmek ve haklarnnda bilimsel araştırmalar gerçekleştirmemek büyük bir eksikliktir. Öyle ki diğer kurumlarn müşterilerinde farkh olarak, kulüplerin aynı zaman da müşterileri olan ve destekçisi olduğu takıma körü körüne bağh olan taraftarlar anlamak kulüpler içinde önemli olacaktır. Bu düşüncelerden hareketle sporla ve özellikle futbolla ilgili olan Spor Bilimleri Fakültesi öğrencilerinin sempatizanı oldukları futbol kulübüne olan psikolojik bağhllklarmın belirlenmesi ve çeşitli değişkenler açısından incelenmesi amaçlanmıştır. Araştırmanın örneklemini Muğla Sıtkı Koçman Üniversitesi Spor Bilimleri Fakültesi'nde eğitim-öğretim görmekte olan 446 öğrenci (162 kadm, 284 erkek) oluşturmuştur. Araştırma kapsaminda kullanilan veri toplama araçlar ise; Mahony, Madrigal ve Howard (2000) tarafindan geliştirilen, Türkçe'ye uyarlaması ve Eskiler, Sarı ve Soyer (2011) tarafindan gerçekleştirilen "Takıma Psikolojik Bağlllık (TPB)" ölçeği ile araştırmacılar tarafindan oluşturulan "Kişisel Bilgi Formu" kullanılmıştır. Öğrencilerden toplanan verilerin analiz edilmesinde; sosyo-demografik özelliklerine göre tanttılması amacryla frekans ve yüzde analizi, çalı̧maya katılan ve ayn zamanda birer futbol taraftarı olan öğrencilerin destekçisi oldukları takıma karşı psikolojik bağhllkklarinı çeşitli değişkenlere göre değerlendirmek amactyla t-testi ve tekyönlü varyans analizi (ANOVA) gerçekleştirilmiştir. Tek yönlü varyans analizi (ANOVA) neticesinde oluşan istatistiksel farkın hangi gruplardan kaynakladığının anlaşılmast için Tukey HSD çoklu karşlaş̧tırma testi yapılmıştır. Tüm verilerin istatistiksel analizlerinde ve yorumlamalarda, $p<0,05$ anlamllık düzeyi dikkate alınmıştır. Araşstırma sonucunda; katılımcllar cinsiyet değişkeni incelendiğinde erkek taraftarların TPB puanlarmm daha yüksek olduğu sonucuna ulaşllmıştır. Öğrencilerin destekçisi oldukları futbol takımı değişkenine bakıldığında Fenerbahçe taraftarı olan katılımolların TPB puanlarının diğer takım destekçilerine kıyasla anlamlı düzeyde daha yüksek olduğu tespit edilmiştir. Araştırmanın diğger bir sonucu ise, futbol takımımın resmi ürünlerini satın almam diyen öğrencilerin TPB puanlarının diğer öğrencilere kuyasla istatistiksel açıdan anlamlı düzeyde düşük olduğu belirlenmiştir

Anahtar Kelimeler: Taraftar, Psikolojik Bă̆lllık, Futbol, Öğrenci.

\footnotetext{
* Bu çalışmanın özeti "6th International Conference on Science Culture and Sport 25-27 April 2018 LvivUkraine" kongresinde sözel olarak sunulmştur.
} 


\title{
The Examination of the Psychological Commitment of the Students in The Faculty of Sport Sciences to The Football Team That They Support
}

\begin{abstract}
Although the fans are one of the main sources that keep the clubs alive, it is extremely wrong to ignore this audience and not to conduct research based on scientific methods about them. It will be important for the clubs to understand this community that is attached blindly and does not stop supporting their team. In this study, the aim was to understand the psychological commitment of the Faculty of Sport Sciences students to the team they support and examine this commitment in terms of different variables. The study group of this research consisted of 446 students, 162 of whom were females and 284 were males, who continue their education at Muğla Sıtkı Koçman University the Faculty of Sport Sciences. As data collection tools; the Psychological Commitment to Team (PCT) Scale developed by Mahony et al. (2000) and adapted to Turkish by Eskiler et al. (2011) and the "Personal Information Form" prepared by the researchers to determine the demographic characteristics of the students were used. In the analysis of the obtained data; to determine the socio-demographic characteristics of the participants, frequency and percentage analysis, and to evaluate the psychological commitment of students to their teams according to different variables t-test and one-way analysis of variance (ANOVA) were applied. After oneway analysis of variance(ANOVA), Tukey HSD multiple comparison test was applied to determine from which groups the statistical difference occurred. In statistical analysis and interpretation of the data, $p<0.05$ significance level was taken into consideration. Taking gender into account, the results of the research showed that male students had higher TPB scores than female ones. In addition, according to the team variable, it was determined that the TPB scores of the students who were fans of Fenerbahçe were significantly higher than the other team fans. According to another result, it was found that the TPB scores of the participants who said that I didn't buy official products were significantly lower than other fans.
\end{abstract}

Keywords: Fans, Psychological Commitment, Football, Student. 


\section{Giriş}

Spor her bireyin hayatında yer eden ve yaşamını etkileyen bir kavramdır. Spor içerisindeki takımlara karşı hissedilen duygusal bağlılık taraftar olma ya da fanatik olma duygusu ile kısıtlı değildir (Demirel, Güven Karahan ve Ünlü, 2007). Günümüzde spor giderek önemli bir hale gelen toplumsal dinamiktir. Çünkü, zamanla çok daha fazla birey tarafından takip edilmeye başlamış, kitleleri peşinden sürükleyen ve uluslararası bir saygınlık prestij gösterisi konumunu almıştır (Togo, 2016). Dünyanın çoğu ülkesinde olduğu gibi bizim ülkemizde de özellikle futbol, kitleleri peşinen sürükleyen ve nüfusun çoğunu yakından ilgilendiği bir değer kazanmış durumdadır. Futbol takımlarının taraftarlarına kendi aralarında diğer takımlar ya da taraftarlarıyla yaşadıkları rekabeti ülkedeki yaşanan bazı politik, ekonomik ve toplumsal olaylarından daha çekici gelmektedir (Koçer, 2012). Ayrıca futbol insanların bir kimlik oluşturmanın yanında, farklı sosyal kimliklerin karşılaşmasına ve birbirlerinden etkilenmesine de katkı sağlamaktadır (Öntürk, Karacabey ve Özbar, 2019).

Bireylerin spor takımlarına karşı oluşturdukları bağlar olduğu ve bağların duygusallık ya da psikoloji ile ilgili olduğu düşünülmektedir (Zorba, Mutlu ve Bayrakdar, 2017). Bu düşünce uzun süreli bir ilişkiyi koruma adına ve süreklilik gerektiren bir arzuyu da ortaya çıkarttığı kanıtlanmıştır (Giray ve Gültekin Salman, 2008). Sosyal bir olgu olan sporun da kişilerde birçok psikolojik ihtiyaç ve bağllık duygusunu ortaya çıkardığı bilinmektedir (Ekici, Öntürk ve Karafil, 2016). Psikolojik bağlılık, birçok faydalı tutum ve davranışları meydana gelmesinde etkin rol oynayan ve sadakat davranışlarını da içine alan bir tutumdur (Tüfekçi ve Bağış, 2016). Her birey genellikle yalnızlığını gidermek amacıyla bağlılık duygusunu kullanmaktadır (Dinç ve Demircan, 2016).

Taraftarların destekçisi oldukları futbol takımlarına ilişkin psikolojik bağlılıkları, özellikle pazarlama alanyazında sıklıkla ilgilenilen müşteri sadakati ve sadık müşteri gibi kavramlardan çok daha farklı olarak ele alınması gerekmektedir (Bozgeyikli, Taşğın ve Eroğlu, 2018). Takım taraftarlarında özellikle bağlılıkların değerlendirebilmek, tutarlı satın alma davranışı ile ölçümlenebilmektedir (Mahony, Modrigal ve Howard, 2000). Son zamanlarda gerçekleştirilen araştırmalarda, spor takımlarının onların destekçisi olan taraftarla- 
rının psikolojik refahı üzerinde de önemli bir etkisi olduğuna dikkat çekmişlerdir (Olawa, Idemudia ve Umeh, 2019). Wann (2006) tarafindan önerilen takım kimliği ve sosyal psikolojik sağlık modeline göre, taraftarların belirli bir spor takımına psikolojik bağlılığı, kişisel iyi oluş açısından büyük önem arz etmektedir.

Taraftar belirli bir takıma karşı bağlılık duygusuna sahip olan, destekçisi olduğu futbol kulübünün sunmakta olduğu hizmetleri belirli bir ücret karş1lığında satın alan kişilerdir. (Kazançoğlu ve Baybars, 2016). Bu kişilerin bazılarının takımlarına olan bağlılığı o kadar fazladır ki, hayatının merkezi konumuna dahi bir futbol kulübünü getirmiş bireylerin olduğu bilinmektedir. Bireylerin takımlarına bağlılık düzeyleri destekledikleri takıma ve sporcularına kendilerini adama seviyelerine göre seyircilik kısmından fanatikliğe hatta holiganlık kısmına kadar ilerleyebilir (Trail ve James, 2001). Takımlarına fanatiklik seviyesinde bağlı olan bireyler takımlarının spor karşılaşmaları esnasinda zaferi elde edebilmesi için her türlü yolu kabul gören, sporun ve sporcunun herhangi bir sınıfinda yer almayan sadece takımlarının zaferini önde tutan kişiler olarak adlandırılır (Arıkan, 2000). Holiganlık ise takımlarının başarılı olmasını istemekten ziyade taraftarlık bağlılığını şiddetli bir şekilde yaşayan ve kendine, çevresine ve kamuya zarar vermekten sakınmayan kişilerdir (Aycan, Polat ve Uçan, 2009). Wann'a (1997) göre destekledikleri takıma karşı bağlılığı yüksek olan taraftarlar kendilerini takıma bağlı bir parça olarak hissederler. Takımların hayatlarının ve benlik merkezlerinin ortasına almaları takımların desteklemeyen diğer takım taraftarından kendilerini üstün olarak görmelerine sebebiyet vermektedir (Alçak ve diğerleri, 2018).

Zaman içerisinde spor olgusunun dahi önüne geçen futbol özellikle toplum üzerinde sadece spor olmaktan çıkmış, başka birçok farklı dinamiği beraberinde taşımasından kaynaklı olarak önemini her geçen gün arttırmaktadır (Göksel, Yıldız, Şenel ve Ekici, 2019). Günümüz spor endüstrisinde en önemli branşlardan biri olan futbolun, bu kadar popüler olmasını sağlayan ve futbol kulüplerinin ekonomik olarak da ayakta durmalarını sağlayan unsur hiç şüphe yok ki kulübün sahip olduğu taraftarlarıdır. Takımlarının çok farklı platformlarda destekleyen taraftarlar, kulüplerinde hiçbir maddi beklentileri olmaksızın destekler ve futbol kulüpleri açısından yalnızca tüketen durumunda olmayı sürdürürler (Bozgeyikli ve diğerleri, 2018). Bu sebeple futbol kulüplerinin en temel gelir kaynağ 1 ve hedef kitlesi olan taraftarlarını görmezden gelmek ve haklarında bilimsel araştırmalar gerçekleştirmemek 
büyük bir eksikliktir. Öyle ki diğer kurumların müşterilerinde farklı olarak, kulüplerin aynı zaman da müşterileri olan ve destekçisi olduğu takıma körü körüne bağlı olan taraftarları anlamak kulüpler içinde önemli olacaktır. Bu düşüncelerden hareketle sporla ve özellikle futbolla ilgili olan Spor Bilimleri Fakültesi öğrencilerinin sempatizanı oldukları futbol kulübüne olan psikolojik bağlılıklarının belirlenmesi ve çeşitli değişkenler açısından incelenmesi amaçlanmıştır.

\section{Yöntem}

\section{Araştırmanın Modeli}

Mevcut araştırma kapsamında, Muğla Sıtkı Koçman Üniversitesi Spor Bilimleri Fakültesi 2017-2018 eğitim-öğretim yılında okuyan öğrencilerle betimsel tarama modelinden yararlanılarak gerçekleştirilmiştir. Alan yazına bakıld1ğında tarama modeli, geçmişte ya da mevcut dönemde olan bir durumu var olduğu biçimde tanımlamayı amaçlayan araştırma yaklaşımıdır. Araştırmaya konu olan olay, birey ya da nesneye, olduğu gibi kendi şartları içerisinde ve müdahale edilmeksizin betimlemeye çalışılır (Karasar, 2016).

\section{Araştırmanın Evreni ve Örneklemi}

Araştırmanın evrenini 2017-2018 yılında Muğla Sıtkı Koçman Üniversitesi Spor Bilimleri Fakültesi'nde eğitim ve öğretimlerine sürdürmekte olan öğrenciler oluşturmaktadır. Araştırmanın araştırma grubunu ise Spor Bilimleri Fakültesi'nde eğitimlerine devam eden ve çalışmaya gönüllü olarak katılan 162'si kadın, 284'ü erkek toplam 446 öğrenci oluşturmuştur. Araştırma kapsamında katılımcılara uygulanan 507 anketin 61 tanesi eksik ya da değerlendirilmeye tabi tutulamayacak biçimde doldurulduğundan araştırma verilerinin içeresine dâhil edilmemiştir.

\section{Veri Toplama Aracı}

Araştırmada kapsamında veri toplama aracı olarak; Mahony ve ark., (2000) tarafından geliştirilen ve Eskiler ve ark., (2011) tarafından Türkçe uyarlaması yapılan “Takıma Psikolojik Bağlılık (TPB)” ölçeği ile araştırmacılar tarafından 
hazırlanan, katılımcıların demografik özelliklerini amacıyla oluşturulan "Kişisel Bilgi Formu" kullanılmıştır. TPB 14 madde ve 3 alt boyuttan (Takım Değişikliğine Direnç, Takıma Duyulan Sadakat ve Sadakati Sorgulama) oluşmakta 7'li likert tipinde (7=Tamamen Katılıyorum, 1=Hiç Katılmıyorum) puanlanmaktadır. Ayrıca araştırmacı tarafından geliştirilen ve spor bilimleri öğrencilerinin cinsiyet, yaş, bölüm, takım, resmi ürün satın alma sıklı̆̆ı, takımın tüm maçların takip etme ve taraftar derneğine üye olma değişkenleri hakkında bilgi edinmeye yönelik kişisel bilgi formu kullanılmıştır. TPB ölçeğinden alınabilecek en yüksek puan 98.00 ve en düşük puan ise 14.00 'dür. TPB ölçeğinde yer alan olumsuz ifadelerin döndürülmesi ile oluşturulan nihai toplam puan, takıma olan bağlılığı göstermektedir, puanın yükselmesi kişinin takımına olan yüksek düzeyde psikolojik bağlılığını işaret etmektedir.

TPB ölçeğinin Cronbach's Alpha iç tutarlık katsayısı gerçekleştirilen analiz sonucunda ",857" olarak belirlenmiştir. Alpha katsayısına bağlı olarak ölçeğin güvenilirliği şu şekilde yorumlanır; $0.00 \leq a l f a \leq 0.40$ ise ölçek güvenilir değildir, $0.40 \leq a l f a \leq 0.60$ ise ölçeğin güvenilirliği düşüktür, $0.60 \leq a l f a \leq 0.80$ ise ölçek oldukça güvenilirdir, $0.80 \leq a l f a \leq 1.00$ ise ölçek yüksek derecede güvenilirdir (Kalaycı, 2008). Mevcut sonuca (,857) göre araştırma sonuçlarının güvenirliği için oldukça yüksek denebilir.

\section{Verilerin Toplanması}

Araştırma amaçları doğrultusunda veri toplamak amaciyla spor bilimleri öğrencilerine ders saati öncesinde ölçek uygulanmıştır. Derse gelen tüm öğrencilere anket formları dağıtılmadan önce araştırmanın amacı ile veri toplama aracı ve veri toplama aracının doğru bir şekilde doldurulmasıyla ilgili olarak ayrıntılı bilgi paylaşımı yapılmıştır. Araştırmada gönüllü katılım ilkesi esas alınmış ve yalnızca araştırmaya gönüllü olarak katılmak isteyen öğrencilere anket formu verilmiştir. Araştırmacı tarafından toplanan anket formları (446 adet) incelenmek üzere elektronik ortama aktarılmıştır.

\section{Verilerin Analizi}

Araştırma doğrultusunda Spor Bilimleri Fakültesi öğrencilerinden elde edilen verilerin analizinde; verilerin normal bir dağılım gösterip göstermediği- 
nin anlaşılması amacıyla normallik testi gerçekleştirilirmiş ve verilerin normal dağılım gösterdiği belirlenmiş ve bu nedenle verilere parametrik testler uygulanmıştır (Tablo-2). Katılımcılardan toplanan verilerin analiz edilmesinde sosyo-demografik özelliklerin anlaşılması amacıyla frekans ve yüzde analizi, öğrencilerin destekledikleri futbol kulübüne ilişkin psikolojik bağlllıklarını farklı değişkenlere göre incelemek amacıyla t-testi ve tekyönlü varyans analizi (ANOVA) yapılmıştır. Tek yönlü varyans analizi (ANOVA) sonucunda tespit edilen istatistiksel farklılığın hangi gruplar arasında olduğunu belirlemek amacıyla Tukey HSD çoklu karşılaştırma testi yapılmıştır. Tüm verilerin istatistiksel analizlerinde ve yorumlamalarında, $\mathrm{p}<0,05$ anlamllık düzeyi göz önünde bulundurulmuştur.

\section{Bulgular}

Tablo 1. Katılımcılarnn Demografik Özelliklerine Göre Dă̆ılımları

\begin{tabular}{llll}
\hline Değişkenler & & $\mathbf{N}$ & $\mathbf{\%}$ \\
\hline \multirow{2}{*}{ Cinsiyet } & Erkek & 284 & 63,7 \\
& Kadın & 162 & 36,3 \\
\hline \multirow{4}{*}{ Bölüm } & BES Öğr. & 76 & 17,0 \\
& Ant. Eğt. & 120 & 26,9 \\
& Spor Yön. & 159 & 35,7 \\
& Rekreasyon & 91 & 20,4 \\
\hline \multirow{2}{*}{ Takım } & Galatasaray & 153 & 34,3 \\
& Fenerbahçe & 127 & 28,5 \\
& Beşiktaş & 98 & 22,0 \\
\multirow{2}{*}{ Resmi Ürün Satın Alma Sıklığı } & Diğer & 68 & 15,2 \\
& Ayda Birkaç Kez & 80 & 17,9 \\
\multirow{2}{*}{ Takımın Tüm Maçlarını Takip Etme Durumu } & Yllda Birkaç Kez & 251 & 56,3 \\
& Hiç Satın Almam & 115 & 25,8 \\
\hline \multirow{2}{*}{ Taraftar Derneğine Üyelik } & Evet & 241 & 54,0 \\
& Hayır & 205 & 46,0 \\
\hline Toplam & Var & 109 & 24,4 \\
& Yok & 337 & 75,6 \\
\hline
\end{tabular}

Tablo-1'de araştırmaya katılan SBF öğrencilerinin demografik bilgilerine ilişkin bilgi verilmektedir. Buna göre araştırmaya dahil olan öğrencilerin \%63,7'si (284 kişi) erkek; \%36,3'ü (162 kişi) ise kadındır. Katılımcıların eğitimöğretim gördükleri bölüm değişkenine bakıldığında \%17,0'si (76 kişi) Beden Eğitimi ve Spor Öğretmenliği, \%26,9'u (120 kişi) Antrenörlük Eğitimi, \%35,7'si (159 kişi) Spor Yöneticiliği ve \%20,4'ü (91 kişi) Rekreasyon Bölümü 
öğrencisidir. Çalışmaya gönüllü olarak katılan SBF öğrencilerinin taraftarı oldukları takıma bakıldığında \%34,3'ü (153 kişi) Galatasaray takımını, \%28,5'i (127 kişi) Fenerbahçe takımını, \%22,0'si (98 kişi) Beşiktaş takımını ve \%15,2'si (68 kişi) diğer takımları desteklemektedir. Resmi ürün satın alma durumlarına bakıldığında ise; SBF öğrencilerinin \%17,9'u (80 kişi) ayda birkaç kez, $\% 56,3$ 'ü yılda birkaç kez ve \%25,8'i (115 kişi) hiç resmi ürün satın almadıklarını belirtmiştir. Katılımcıların destekçisi oldukları takımın tüm maçlarını takip etme durumlarına bakıldığında ise \%54,0'ünün (241 kişi) takımlarının tüm maçlarını izledikleri ve \%46,0'sının (205 kişi) ise maçların tamamın izlemedikleri belirlenmiştir. SBF öğrencilerinin \%24,4'ünün (109 kişi) taraftar derneğine üyeliği bulunurken \%75,6'sının (337 kişi) hiçbir taraftar derneğine üye olmadıkları görülmektedir.

Tablo 2. Ölçek Puan Dağılımı

\begin{tabular}{llllllll}
\hline & N & Min. & Max. & Ort. & Ss & Çarpıklık & Basıklık \\
\hline TPBÖ & 446 & 38,00 & 98,00 & 5,35 & 1,13 &,- 477 &,- 717 \\
\hline
\end{tabular}

Araştırma kapsamında SBF öğrencilerinin “Takıma Psikolojik Bağlılık Ölçeğinden" (TPBÖ) aldıkları puanların aritmetik ortalaması 5,35'dir. Çarpıklık $(-, 477)$ ve basıklık $(, 717)$ katsayıları incelendiğinde öğrencilerden elde edilen verilerin normal bir dağılıma gösterdiği belirlenmiştir. Standart sapmanın da 1,13 olduğu görülmektedir (Tablo-2).

Tablo 3. Katılımcılarn Cinsiyet Değişkenine Göre TPBÖ t-Testi Sonuçlarn

\begin{tabular}{|c|c|c|c|c|c|c|}
\hline Alt boyutlar & Cinsiyet & $\mathbf{N}$ & Ort. & Ss. & $t$ & $p$ \\
\hline \multirow{2}{*}{ ТРВÖ } & Erkek & 284 & 5,49 & 1,14 & \multirow{2}{*}{3,377} & \multirow{2}{*}{, $001^{*}$} \\
\hline & Kadın & 162 & 5,12 & 1,10 & & \\
\hline \multirow{2}{*}{ Takım Değişikliğine Direnç } & Erkek & 284 & 5,60 & 1,41 & \multirow{2}{*}{2,450} & \multirow{2}{*}{, $015^{*}$} \\
\hline & $\underline{\text { Kadın }}$ & 162 & 5,26 & 1,43 & & \\
\hline \multirow{2}{*}{ Takıma Duyulan Sadakat } & Erkek & 284 & 4,85 & 1,70 & \multirow{2}{*}{3,471} & \multirow{2}{*}{, $001^{*}$} \\
\hline & Kadın & 162 & 4,30 & 1,58 & & \\
\hline \multirow{2}{*}{ Sadakati Sorgulama } & Erkek & 284 & 6,31 & 0,78 & \multirow{2}{*}{1,380} & \multirow{2}{*}{,172 } \\
\hline & Kadın & 162 & 6,20 & 0,75 & & \\
\hline
\end{tabular}

${ }^{*} p<0,05$

Tablo-3'e bakıldığında cinsiyet değişkene göre; Spor Bilimleri Fakültesi öğrencilerinin ölçeğin genelinde $(p=, 001<0,05)$, takım değişikliğine direnç $(p=, 015<0,05)$ ve takıma duyulan sadakat $(p=, 001<0,05)$ alt boyutlarında erkek öğrenciler lehine istatistiksel olarak anlamlı farklılıklar tespit edilmiştir. 
Tablo 4. Katılımcılarn Bölüm Değişkenine Göre TPBÖ ANOVA Sonuçları

\begin{tabular}{|c|c|c|c|c|c|c|c|}
\hline Alt boyutlar & Bölüm & $\mathbf{N}$ & Ort. & Ss. & $\mathbf{F}$ & $p$ & Post-Hoc \\
\hline \multirow{4}{*}{ TPB } & BES Öğr. & 76 & 5,02 & 1,05 & \multirow{4}{*}{3,027} & \multirow{4}{*}{, $029^{*}$} & \multirow{4}{*}{ Spor Yön. > BES Öğr. } \\
\hline & Ant. Eğt. & 120 & 5,37 & 1,12 & & & \\
\hline & Spor Yön. & 159 & 5,48 & 1,10 & & & \\
\hline & Rek. & 91 & 5,39 & 1,23 & & & \\
\hline \multirow{4}{*}{ Takım Değişikliğine Direnç } & BESÖğr. & 76 & 5,27 & 1,32 & \multirow{4}{*}{859} & \multirow{4}{*}{462} & \multirow{4}{*}{-} \\
\hline & Ant. Eğt. & 120 & 5,47 & 1,39 & & & \\
\hline & Spor Yön. & 159 & 5,59 & 1,43 & & & \\
\hline & Rek. & 91 & 5,48 & 1,56 & & & \\
\hline \multirow{4}{*}{ Takıma Duyulan Sadakat } & BES Öğr. & 76 & 4,09 & 1,58 & \multirow{4}{*}{3,749} & \multirow{4}{*}{, $011^{*}$} & \multirow{4}{*}{$\begin{array}{l}\text { Spor Yön. > BES Öğr. } \\
\text { Ant. Eğt. > BES Öğr. }\end{array}$} \\
\hline & Ant. Eğt. & 120 & 4,72 & 1,61 & & & \\
\hline & Spor Yön. & 159 & 4,86 & 1,69 & & & \\
\hline & Rek. & 91 & 4,67 & 1,76 & & & \\
\hline \multirow{4}{*}{ Sadakati Sorgulama } & $\overline{\text { BES Öğr. }}$ & 76 & 6,05 & 0,82 & \multirow{4}{*}{3,059} & \multirow{4}{*}{, $028^{*}$} & \multirow{4}{*}{ Rekreas. > BES Öğr. } \\
\hline & Ant. Eğt. & 120 & 6,24 & 0,80 & & & \\
\hline & Spor Yön. & 159 & 6,32 & 0,74 & & & \\
\hline & Rek. & 91 & 6,39 & 0,71 & & & \\
\hline
\end{tabular}

${ }^{*} p<0,05$

Ölçeğin ve üç alt boyutuna ilişkin ortalama ve standart sapma değerleri ile bölüm değişkenine ilişkin yapılan tek yönlü varyans analizi (Anova) sonucu Tablo-4'te gösterilmiştir. Buna göre, Spor Bilimleri Fakültesi öğrencilerinin TPBÖ'nin genelinde $(\mathrm{p}=, 029<0.05)$, takıma duyulan sadakat $(p=, 011<0.05)$ ve sadakati sorgulama $(p=, 028<0.05)$ alt boyutlarında bölüm değişkenine göre istatistiksel açıdan anlamlı farklılık göstermektedir.

Tablo 5. Katılımcıların Takım Değişkenine Göre TPBÖ ANOVA Sonuçları

\begin{tabular}{|c|c|c|c|c|c|c|c|}
\hline Alt boyutlar & Takım & $\mathbf{N}$ & Ort. & Ss. & $\mathbf{F}$ & $p$ & Post-Hoc \\
\hline \multirow{4}{*}{ TPB } & GS & 153 & 5,30 & 1,14 & \multirow{4}{*}{3,924} & \multirow{4}{*}{, $009^{*}$} & \multirow{4}{*}{ FB $>$ Diğer } \\
\hline & FB & 127 & 5,55 & 1,04 & & & \\
\hline & BJK & 98 & 5,43 & 1,06 & & & \\
\hline & Diğger & 68 & 4,99 & 1,30 & & & \\
\hline \multirow{4}{*}{ Takım Değişikliğine Direnç } & GS & 153 & 5,48 & 1,45 & \multirow{4}{*}{5,842} & \multirow{4}{*}{, $001^{*}$} & \multirow{4}{*}{$\begin{array}{l}\text { GS }>\text { Diğer } \\
\text { FB }>\text { Diğer } \\
\text { BJK }>\text { Diğer }\end{array}$} \\
\hline & FB & 127 & 5,76 & 1,26 & & & \\
\hline & BJK & 98 & 5,53 & 1,30 & & & \\
\hline & Diğer & 68 & 4,88 & 1,67 & & & \\
\hline \multirow{4}{*}{ Takıma Duyulan Sadakat } & GS & 153 & 4,54 & 1,69 & \multirow{4}{*}{2,040} & \multirow{4}{*}{108} & \multirow{4}{*}{-} \\
\hline & FB & 127 & 4,89 & 1,59 & & & \\
\hline & BJK & 98 & 4,75 & 1,61 & & & \\
\hline & Diğer & 68 & 4,32 & 1,88 & & & \\
\hline \multirow{4}{*}{ Sadakati Sorgulama } & GS & 153 & 6,21 & 0,77 & \multirow{4}{*}{1,329} & \multirow{4}{*}{ 264 } & \multirow{4}{*}{-} \\
\hline & FB & 127 & 6,22 & 0,75 & & & \\
\hline & BJK & 98 & 6,39 & 0,76 & & & \\
\hline & Diğer & 68 & 6,31 & 0,82 & & & \\
\hline
\end{tabular}

${ }^{*} p<0,05$ 
Tablo-5'de SBF öğrencilerinin taraftarı oldukları takım değişkenlerine göre TPBÖ'nden aldıkları puanlara bakıldığında, ölçeğin genelinde $(p=, 009<0,05)$ ve takım değişikliğine direnç $(p=, 001<0,05)$ alt boyutunda istatistiksel açıdan anlamlı farklılık tespit edilmiştir. Fakat takıma duyulan sadakat $(p=, 108>0,05)$ ve sadakati sorgulama $(p=, 264>0,05)$ alt boyutlarında istatistiksel olarak anlamlı farklılık bulunamamıştır.

Tablo 6. Katılımcılarnn Resmi Ürün Satın Alma Değişkenine Göre TPBÖ ANOVA Sonuçlan

\begin{tabular}{|c|c|c|c|c|c|c|c|}
\hline Alt boyutlar & R. Ürün Satın Alma & $\mathbf{N}$ & Ort. & Ss. & F & $p$ & Post-Hoc \\
\hline \multirow{3}{*}{ TPB } & 1-Ayda Bir Kaç kez & 80 & 5,56 & 1,06 & \multirow{3}{*}{36,411} & \multirow{3}{*}{, $000^{*}$} & \multirow{3}{*}{$\begin{array}{l}1>3 \\
2>3\end{array}$} \\
\hline & 2-Yılda Bir Kaç Kez & 251 & 5,62 & 1,03 & & & \\
\hline & 3-Hiç Satın Almam & 115 & 4,63 & 1,09 & & & \\
\hline \multirow{3}{*}{ Takım Değişikliğine Direnç } & 1-Ayda Bir Kaç kez & 80 & 5,65 & 1,32 & \multirow{3}{*}{21,771} & \multirow{3}{*}{, $000^{*}$} & \\
\hline & 2-Yılda Bir Kaç Kez & 251 & 5,75 & 1,32 & & & $2>3$ \\
\hline & 3-Hiç Satın Almam & 115 & 4,76 & 1,49 & & & \\
\hline \multirow{3}{*}{ Takıma Duyulan Sadakat } & 1-Ayda Bir Kaç kez & 80 & 4,98 & 1,60 & \multirow{3}{*}{38,463} & \multirow{3}{*}{, $000^{*}$} & \\
\hline & 2-Yılda Bir Kaç Kez & 251 & 5,05 & 1,54 & & & $1>3$ \\
\hline & 3-Hiç Satın Almam & 115 & 3,55 & 1,55 & & & \\
\hline \multirow{3}{*}{ Sadakati Sorgulama } & 1-Ayda Bir Kaç kez & 80 & 6,34 & 0,76 & \multirow{3}{*}{1,302} & \multirow{3}{*}{273} & \multirow{3}{*}{-} \\
\hline & 2-Yılda Bir Kaç Kez & 251 & 6,29 & 0,76 & & & \\
\hline & 3-Hiç Satın Almam & 115 & 6,17 & 0,80 & & & \\
\hline
\end{tabular}

${ }^{*} p<0,05$

Takıma psikolojik bağlllık ölçeğin ve üç alt boyutuna ilişkin ortalama ve standart sapma değerleri ile resmi ürün satın alma durumu değişkenine ilişkin yapılan tek yönlü varyans analizi (ANOVA) sonucu Tablo-6'da gösterilmiştir. Buna göre, Spor Bilimleri Fakültesi öğrencilerinin TPBÖ'nin genelinde $(p=, 000<0.05)$, takım değişikliğine direnç $(p=, 000<0.05)$ ve takıma duyulan sadakat $(p=, 000<0.05)$ alt boyutlarında resmi ürün satın alma durumu değişkenine göre istatistiksel açıdan anlamlı farklılık tespit edilmiştir. Resmi ürün satın alma sıklığı artıkça takıma duyulan psikolojik bağlılık artmaktadır. 
Tablo 7. Katılımcıların Takımın Taraftar Derneğine Üyeliği Değişkenine Göre TPB t-Testi Sonuçlarn

\begin{tabular}{|c|c|c|c|c|c|c|}
\hline Alt boyutlar & Taraftar Derneğine Üyelik & $\mathbf{N}$ & Ort. & Ss. & $\mathrm{t}$ & $p$ \\
\hline \multirow{2}{*}{ ТРВӦ } & Var & 109 & 5,73 & 1,07 & \multirow[b]{2}{*}{4,227} & \multirow[b]{2}{*}{, $000^{*}$} \\
\hline & Yok & 337 & 5,23 & 1,13 & & \\
\hline \multirow[b]{2}{*}{ Takım Değişikliğine Direnç } & Var & 109 & 5,86 & 1,25 & \multirow[b]{2}{*}{3,487} & \multirow[b]{2}{*}{, $001^{*}$} \\
\hline & Yok & 337 & 5,36 & 1,46 & & \\
\hline \multirow{2}{*}{ Takıma Duyulan Sadakat } & Var & 109 & 5,17 & 1,74 & \multirow[b]{2}{*}{3,596} & \multirow{2}{*}{, $000^{*}$} \\
\hline & Yok & 337 & 4,48 & 1,63 & & \\
\hline \multirow{2}{*}{ Sadakati Sorgulama } & Var & 109 & 6,43 & 0,69 & \multirow[b]{2}{*}{ 2,799 } & \multirow[b]{2}{*}{, $006^{*}$} \\
\hline & Yok & 337 & 6,21 & 0,79 & & \\
\hline
\end{tabular}

${ }^{*} p<0,05$

Ölçeğin ve üç alt boyutuna ilişkin ortalama ve standart sapma değerleri ile katılımcların takımın taraftar derneklerine üye olma durumu değişkenine ilişkin yapılan t-testi analizi sonucu Tablo-8' de gösterilmiştir. Buna göre, Spor Bilimleri Fakültesi öğrencilerinin TPBÖ'nin genelinde $(p=, 000<0.05)$, takım değişikliğine direnç $(p=, 000<0.05)$, takıma duyulan sadakat $(p=, 000<0.05)$ ve sadakati sorgulama $(\mathrm{p}=, 006<0.05)$ alt boyutlarında takımın taraftar derneklerine üye olma durumu değişkenine göre istatistiksel açıdan anlamlı farklılık olduğu görülmektedir.

\section{Tartışma}

Mevcut araştırma, Spor Bilimleri Fakültesi öğrencilerinin taraftarı oldukları futbol takımına olan psikolojik bağlılıklarının belirlenmesi ve kulüplerine karşı sahip oldukları psikolojik bağlılıklarının farklı değişkenler açısından karşılaştırılması amacıyla gerçekleştirilmiştir.

Araştırmaya dâhil olan spor bilimleri öğrencilerinden elde edilen bulgular neticesinde, erkek öğrencilerin kadın öğrencilere göre destekçisi oldukları spor kulübüne karşı psikolojik bağlılıklarının daha fazla olduğu ve bu farklılığın istatistiksel açıdan anlamlı düzeyde olduğu belirlenmiştir. Literatüre bakıldığında, Gençay ve Karaküçük'ün (2006) spor taraftarlığıyla ilgili olarak üniversite öğrencilerini dahil ettiği çalışmada erkek öğrenciler lehine anlamlı farklılık tespit ettiği görülmüştür. Ayrıca Giray ve Salman (2008); Sarı, Eskiler ve Soyer, (2011) yaptıkları araştırmalarda erkek katılımcıların kadın katılımcılara oranla takımlarına karşı psikolojik bağlılık düzeylerinin yüksek olduğu 
ve araştırmamamızla benzer şekilde anlamlı olarak farklılaştığı sonucuna ulaşmıştır.

Bölüm değişkenine göre spor bilimleri öğrencilerinin destekçisi oldukları takıma ilişkin psikolojik bağlllıklarında Spor Yöneticiliği Bölümü öğrencilerinin en yüksek ortalamaya sahip olduğu ve Beden Eğitimi ve Spor Öğretmenliği bölümü öğrencilerinden istatistiksel açıdan anlamlı farklılığa sahip olduğu belirlenmiştir. Bozyiğit ve Doğan'ın (2018) yapmış oldukları çalışmada bölüm değişkenine göre üniversite öğrencilerinin takıma psikolojik bağlllıklarında anlamlı farklılık tespit etmişlerdir ve bu yönüyle araştırmamızı destekler nitelikte sonuca ulaşmışlardır. Ölçeğin genelinde ve tüm alt boyutlarında en düşük psikolojik bağlılık düzeyi BES Öğretmenliği ve Antrenörlük Eğitimi bölümü öğrencilerinde olduğu belirlenmiş, bu doğrultuda BES Öğretmenliği ve Antrenörlük Eğitimi bölümü öğrencilerinin mezun olduktan sonra çeşitli spor kulüplerinde çalışma ihtimali bulunmasından kaynaklı daha objektif düşünme eğiliminde oldukları söylenebilir.

Spor Bilimleri alanında okuyan öğrencilerin destekçisi oldukları takım değişkenine göre ölçeğinde genelinde Fenerbahçe taraftarlarının Diğer takım taraftarlarına göre psikolojik bağlllıklarının daha fazla olduğu belirlenmiştir. Takım değişikliğine direnç alt boyutunda ise üç büyük kulübün taraftarları lehine Diğer takım tarafları arasında anlamlı farklılık olduğu sonucuna ulaşılmıştır.

Katılımcların taraftarı oldukları futbol kulübünün resmi ürünlerini satın alam durumları incelendiğinde, "Ayda birkaç kez" ve "Yılda birkaç kez" resmi ürün satın alırım diyenlerin "Hiç satın almam" diyenlere kıyasla takımlarına karşı psikolojik bağllıı düzeylerinin çok daha yüksek olduğu belirlenmiştir. Bu farklılık istatistiksel açıdan anlamlı düzeyde bulunmuştur. Alan yazın incelendiğinde Bozyiğit ve Doğan'ın (2018) gerçekleştirdiği araştırmada lisanslı ürün satın alan katılımcıların almayanlara kıyasla takımlarına karşı psikolojik bağlılıklarının yüksek olduğu sonucuna ulaştıkları anlaşılmıştır. Ulusal ve uluslararası benzer çalışmalar incelendiğinde Harolle, Trail, Rodriguez ve Jordan (2010); Eskiler ve ark., (2011); Tüfekçi ve Bağış (2016) yapmış oldukları araştırmalarda takımlarına psikolojik bağlılıkları yüksek olan taraftarların destekledikleri takımın lisanslı ve resmi ürünlerini daha fazla satın alma eğiliminde oldukları sonucuna ulaşmışlar ve bu durum araştırmamızın sonuçlarıyla paralellik göstermektedir. 
Elde edilen veriler doğrultusunda spor bilimleri öğrencilerinden destekçisi oldukları takımın Taraftar gruplarına üyeliği bulunanların ölçeğin genelinde ve tüm alt boyutlarında üye olmayanlara göre takımlarına olan psikolojik bağlılık düzeylerinin istatistiksel bakımdan anlamlı düzeyde farklılaştığı ve takımlarıyla daha fazla özdeşleştikleri sonucuna ulaşılmıştır.

\section{Sonuç}

Gerçekleştirilen bu çalışmada Muğla Sıtkı Koçman Üniversitesi Spor Bilimleri Fakültesi'nde öğrenimlerine devam eden öğrencilerin destekçisi oldukları futbol takımlarına karşı psikolojik bağllıkları incelenmiştir. Katılımcılardan elde edilen veriler ışığında, öğrencilerin futbol takımına psikolojik bağlılığının cinsiyete, öğrenim gördüğü bölüme, taraftarı olunan futbol takımına, resmi ürün satın alma sıklığına ve takımın taraftar derneklerine üye olma durumuna göre değişiklik gösterdiği sonucuna ulaşılmıştır. Bu sonuçlar doğrultusunda takımlarına psikolojik bağlılık düzeyleri yüksek olan bireylerin kulüplerinin resmi ürünlerini daha fazla satın alma eğilimde oldukları ve takımlarının taraftar derneklerine üye olma niyetinde oldukları söylenebilir. Özellikle ülkemizde üç büyük kulüp olarak bilinen Galatasaray, Fenerbahçe ve Beşiktaş futbol kulübünün taraftarı olan öğrencilerin takım değişikliğine diğer takım taraftarlarına göre çok daha fazla direnç gösterdikleri belirlenmiştir.

Sonuç olarak araştırmaya gönüllü olarak dahil olan Spor Bilimleri Fakültesi öğrencilerinin destekçisi oldukları futbol takımına karşı yüksek derecede psikolojik bağlılıklarının olduğu tespit edilmiştir.

İlerleyen dönemde benzer konuda çalışmalara ve özellikle bireylerin takımlarına bağlılıklarının gelişmesine katkıda bulunan diğer faktörlerin incelenmesi adına çok daha fazla araştırmaya ihtiyaç duyulduğu söylenebilir. Öyle ki araştırmacilar, bireysel özelliklerin ve sosyal-durumsal faktörlerin davranışsal sadakatin geliştirilmesinde önemli rolü olduğuna dikkat çekmişlerdir (Iwasaki ve Havitz, 1998). Ayrıca spor taraftarları ve hayranların bağl1lıkları üzerine çalışmaların yapılması spor yöneticilerinin taraftarlarının gelecekteki davranışlarını daha fazla anlamalarına ve tahmin etmelerine yardımcı olacağından önemli olduğu düşünülmektedir.

Mevcut çalışmada futbol takım taraftarlarına odaklanılmıştır, gelecekte yapılacak çalışmalarda diğer seyir sporlarındaki araştırmalar yeni ve farklı bulgularla sonuçlanabilir. 


\title{
EXTENDED ABSTRACT
}

\section{The Examination of the Psychological Commitment of the Students in The Faculty of Sport Sciences to The Football Team That They Support}

\author{
Ali Gürel Göksel - Ercan Zorba - Mevlüt Yıldız - Çağdaş Caz \\ Muğla Sıtkı Koçman University, Yozgat Bozok University
}

Sport is a concept that affects everyone's life. Emotional commitment to sports teams is not limited to the feeling of being a supporter or fanatic (Demirel, Güven Karahan, and Ünlü, 2007). Today, sport is a social dynamic that has become increasingly important. In Turkey, as in many countries of the world, football is a sports branch in which the vast majority of the population is closely interested. Competition among football teams is more interesting to fans than the country's various political and economic problems (Koçer, 2012).

It is thought that individuals are attached to sports teams and this attachment is related to emotional or psychological states (Zorba, Mutlu and Bayrakdar, 2017). Also, this situation reveals a desire that requires continuity to maintain a long-term relationship (Giray and Gültekin Salman, 2008). Sports, as a social phenomenon, reveals many psychological needs and loyalty feelings for individuals (Ekici, Öntürk and Karafil, 2016). Psychological commitment is an attitude that reveals many useful behaviours including loyalty behaviours (Tüfekçi \& Bağış, 2016). Each individual generally uses the sense of commitment to relieve their loneliness (Dinç and Demircan, 2016).

The psychological commitment of the football teams that the fans support, should be handled differently from concepts such as customer loyalty and loyal customer, which are frequently researched in the marketing literature (Bozgeyikli, Taşğin and Eroğlu, 2018). The commitment of team fans can be measured by consistent purchasing behaviour (Mahony, Modrigal, and Howard, 2000). Recent research has pointed out that sports teams have a significant impact on the psychological well-being of their fans (Olawa, Idemudia, and Umeh, 2019). According to the team identification-social psychological health model proposed by Wann (2006), the psychological commitment 
of the fans to a particular sports team is of great importance for personal wellbeing.

In today's sports industry, the factor that makes football so popular and keeps football clubs to alive economically is undoubtedly the fans of the club. The fans support their teams without any financial expectations from the team and they are seen as only consumers by clubs (Bozgeyikli et al., 2018). For this reason, it is a great deficiency to ignore the fans of football clubs, which are the main source of income and target audience, and not to conduct research based on scientific methods about them. In fact, unlike the customers of other institutions, it is important for clubs to understand the fans who are the customers and blindly attached to the team they support. Based on these thoughts, this study aims to determine the psychological commitment of the Faculty of Sport Science students, who are interested in sports, especially football, to the football club they support and to analyse this commitment in terms of various variables.

The population of this research consists of the students studying at Muğla S1tkı Koçman University Faculty of Sport Sciences in 2017-2018. The research group consists of 446 students, 162 of whom are female and 284 are male and they voluntarily participated in the study. Although 507 scales were applied for the study, 61 scales were not included in the research data since they were filled in an incomplete or unsuitable for evaluation.

As a data collection tools in this research; the Psychological Commitment to Team (PCT) Scale developed by Mahony et al. (2000) and adapted to Turkish by Eskiler et al. (2011) and "Personal Information Form" prepared by the researchers to determine the demographic characteristics of the participants were used. PCT consists of 14 items and 3 sub-dimensions (Resistance to Team Change, Loyalty to the Team, and Questioning Loyalty) and it is scored in 7-point Likert type ( $7=\mathrm{I}$ totally agree, $1=$ never agree). The total score obtained after the return of the negative items in the PCT scale indicates the commitment to the team. Increased scores indicate a high level of psychological commitment to one's team. In addition, Personal Information Form which was prepared by the researcher was used to get information about the variables of gender, age, department, team, official product purchasing frequency, following all matches of the team and being a member of the fan association. 
In order to collect data for research purposes, data collection tools were applied to students before the lesson start.

In line with the research, for the analysis, the obtained data from the students the normality test was carried out to understand whether the data showed normal distribution. This analysis revealed that the data showed normal distribution, therefore, parametric tests were applied to the data (Table2). In order to determine the socio-demographic characteristics of the participants, frequency and percentage analysis, and to evaluate the psychological commitment of students to their teams according to different variables, $t$-test and one-way analysis of variance (ANOVA) were applied. After a one-way analysis of variance(ANOVA), Tukey HSD multiple comparison tests were applied to determine from which groups the statistical difference occurred. In the statistical analysis and interpretation of all data, $\mathrm{p}<0.05$ significance level was taken into consideration.

In this study, the psychological commitment of the students studying at the Faculty of Sport Sciences to the football teams they support was examined. In the light of the data obtained from the participants, it was concluded that the psychological commitment of the students to the football team they support, varies according to the gender, the department they studying, the football team they support, official product purchase frequency and being a member of the fan association. In line with these results, it can be said that individuals with a high psychological commitment to the team tend to purchase more of their club's official products and they intend to become a member of the fan associations of their teams. It is determined that the students who are the fans of Galatasaray, Fenerbahçe and Beşiktaş football club, known as three big clubs in Turkey, show much more resistance to team change than other team fans. As a result, it was determined that the students participating in the research have a high psychological commitment to the football team they support.

\section{Kaynakça / References}

Alçak, M., Düz, S., Karataş, Ö., Karademir, T., Kurak, K. ve Bayer, R., (2018). Türkiye Futbol Federasyonu 1.Ligindeki taraftarlarının fanatiklik durumlarının incelenmesi. Atatürk Üniversitesi Beden Eğitimi ve Spor Bilimleri Dergisi, 20(3), 8-23. 
Arıkan, A. N. (2000). Farklı branşlardaki spor seyircilerinin sosyo-kültürel profili ve izleyicilik durumları üzerine bir araştırma. Yayımlanmamış doktora tezi, Gazi Üniversitesi, Ankara, Türkiye.

Aycan, A., Polat, E. ve Uçan, Y., (2009). Takım özdeşleşme düzeyi ile profesyonel futbol müsabakalarına seyirci olarak katılım kararını etkileyen değişkenler arasındaki ilişkinin incelenmesi. Spormetre Beden Ĕ̆itimi ve Spor Bilimleri Dergisi, 4, 169-174.

Bozgeyikli, H., Taşğın, Ö., ve Eroğlu, S. (2018). Taraftar psikolojik bağlılık ölçeği Türkçe formunun geçerlik ve güvenirlik çalışması. OPUS Uluslararası Toplum Araştırmaları Dergisi, 9(16), 481-497. DOI: 10.26466/opus.481001

Bozyiğit, E., ve Doğan, F. (2018). Examination of the psychological commitment to team of the students of Faculty of Sports Sciences. Journal of Human Sciences, 15(4), 2159-2167.

Demirel, M., Güven Karahan, B. ve Ünlü, H., (2007). Farklı üniversitelerdeki spor taraftarlarının takımları ile özdeşleşme düzeyleri. Niğde Üniversitesi Beden Ĕ̆itimi ve Spor Bilimleri Dergisi, 1(2), 76-86.

Dinç, S. C. ve Demircan, M., (2016). Tribünde güncel tartışma; takıma psikolojik bağlılığın Passolig uygulamasına ilişkin taraftar görüşleri üzerine etkisi. CBÜ Beden Ĕ̆itimi ve Spor Bilimleri Dergisi, 11(2), 25-38.

Ekici, S., Öntürk, Y., ve Karafil, A. Y. (2016). Spor eğitimi veren yükseköğretim kurumlarında öğrenim gören öğrencilerin temel psikolojik ihtiyaçlarinin incelenmesi. Journal of Human Sciences, 13(3), 3885-3894.

Eskiler, E., Sarı, İ., ve Soyer, F. (2011). Takıma psikolojik bağlılık ölçeğinin Türkçe formunun geçerlilik ve güvenirlik çalışması. Uluslararası İnsan Bilimleri Dergisi, 8(1), 1428-1440.

Gençay, S. ve Karaküçük, S. (2006). Üniversite öğrencilerinin spor taraftarl1ğıyla ilgili davranışları üzerine bir araştırma. Gazi Beden Eğitimi ve Spor Bilimleri Dergisi (Gazi BESBD), 4, 11-22.

Giray, C. ve Gültekin Salman, G., (2008). Fenerbahçe taraftarlarının takımlarına yönelik psikolojik bağlılıkları ile saldırganlıkla ilgili tutumları arasındaki ilişkisi. İstanbul Ticaret Üniversitesi Sosyal Bilimler Dergisi, 13, 147-157.

Göksel, A. G., Yıldız, M. Şenel, E. ve Ekici, S. (2019). Futbol taraftarlarının kulüp imaj1 alg1sı. Journal of Social and Humanities Sciences Research, 6(46), 4032-4037. 
Günay, N. ve Tiryaki, Ş. (2003). Spor taraftarı özdeşleşme ölçeğinin (STÖÖ) geçerlilik ve güvenirlik çalışması. Spor Bilimleri Dergisi, 14(1), 14-26.

Harolle, M., Trail, G., Rodriguez, A. ve Jordan, J. (2010). Conative loyalty of latino and Non- Latino Professional Baseball fans. Journal of Sport Management, 24, 456-471.

Iwasaki, Y. ve Havitz, E.M. (1998). A path analytic model of the relationship between involvement, psychological commitment and loyalty. Journal of Leisure Research, 19(2), 256-280.

Kalaycı, S. (2008). SPSS uygulamalı çok değişkenli istatistik teknikleri. Asil Yayın Dağıtım. Ankara.

Karasar, N. (2016). Bilimsel araştırma yöntemi: Kavramlar ilkeler teknikler. 30. Basım. Nobel Akademik Yayıncllık, Ankara.

Kazançoğlu, İ. ve Baybars, M. (2016). Lisanslı spor ürünlerinin algılanan değer bileşenlerinin satın alma niyeti ile ilişkisi: Türkiye'nin en büyük üç futbol kulübünün incelenmesi. Doğuş Üniversitesi Dergisi, 17(1), 51-66.

Koçer, M. (2012). Futbol derneklerine üye olan taraftarların şiddet ve holiganizm eğilimlerinin belirlenmesi: Kayseri örneği. Sosyal Bilimler Enstitüsü Derneği, 32(1), 111-135.

Mahony D. F., Madrigal R. ve Howard D. (2000). Using the psychological commitment to team (PCT) scale to segment sport consumers based on loyalty. Sport Marketing Quarterly, 9(1), 15-25.

Olawa, B. D., Idemudia, E. S., ve Umeh, C. S. (2019). The Association Between Psychological Commitments to Team and Mental Health of Football Fans Within an Academic Setting. Journal of Happiness Studies, 1-11. DOI: 10.1007/s10902-019-00142-6

Öntürk, Y., Karacabey, K., ve Özbar, N. (2019). Günümüzde spor denilince ilk akla neden futbol gelir? Sorusu üzerine bir araştırma. Spormetre Beden Eğitimi ve Spor Bilimleri Dergisi, 17(2), 1-12.

Sarı, İ., Eskiler, E. ve Soyer, F. (2011). Does psychological commitment to team enhance self-esteem? An easy way to raise self-esteem. International Journal of Humanities and Social Science, 1(19),187-196.

Togo, O. T. (2016). Orta Öğretim öğrencilerinin serbest zamanda yaptıkları spor aktivitesinin kişilik yapıları üzerine etkisi. Marmara Üniversitesi Spor Bilimleri Dergisi, 1(1), 75-87.

Trail, G. T. ve James, J. D., (2001). The motivation scale for sport consumption: Assessment of the scales psychometric properties. Journal of Sport Behavior, 24(2), 108-128. 
Tüfekçi, Ö. K. ve Bağış, Y. E., (2016). Effect of quality perception for psychological commitment, identification levels licensed products on purchase intention of the supporter. Journal of Current Researches on Social Sciences, 6(1), 103-116.

Wann, D. L. (1997). Sports psychology. New Jersey-Hall, 325-67.

Wann, D. L. (2006). Understanding the positive social psychological benefits of sport team identification: The team identification-social psychological health model. Group Dynamics: Theory, Research, and Practice, 10, 272-296.

Zorba, E., Mutlu, T. O. ve Bayrakdar, A. (2017). An evaluation of Turkish police officer's view on violence in football and hooliganism. The Online Journal of Recreation and Sport, 6 (4), 1-12.

\section{Kaynakça Bilgisi / Citation Information}

Göksel, A. G., Zorba, E., Yıldız, M. ve Caz, Ç.(2020) Spor bilimleri fakültesi öğrencilerinin taraftarı oldukları futbol takımına karşı psikolojik bağlılıklarının incelenmesi. OPUS-Uluslararası Toplum Araştırmalart Dergisi , 15(25), 3800-3818. DOI: 10.26466/opus.623549 